\title{
Coupling and Coordination Analysis of Comprehensive Benefits of Water Conservancy Scenic: Taking Qingpu District of Shanghai as an Example
}

\author{
Liu Xianyu ${ }^{1}$, Yang Xuejun ${ }^{2, *}$, and Pan Jun ${ }^{3}$ \\ ${ }^{1}$ Tongji University, Institute of New Rural Development, 201804, Shanghai, China \\ ${ }^{2}$ Tongji University, Institute of New Rural Development, 201804, Shanghai, China \\ ${ }^{3}$ Tongji University, Institute of New Rural Development, 201804, Shanghai, China
}

\begin{abstract}
Based on the domestic comprehensive evaluation methods for water conservancy scenic spots, water environment, and water resources, this paper constructs a comprehensive benefits evaluation index system for water conservancy scenic from both ecological and social benefits. Then, it takes the Qingpu District of Shanghai as the research object, using the entropy method to calculate the comprehensive benefits index of the two major subsystems of ecology and society from 2009 to 2019. Based on that, it concludes that the overall coupling and coordination level of the ecological and social benefits of water conservancy scenic slowly rises at this stage but remains the low-level coupling coordination stage. Finally, from the perspective of improving the comprehensive benefits of water conservancy scenic, it puts forwards the development of Qingpu District towards the beautiful prospect of the harmonious co-existence between human and nature.
\end{abstract}

\section{Introduction}

According to the "Administrative Measures for Water Conservancy Scenic Areas" issued in 2004, water conservancy landscape resources refer to waters (water bodies) and associated shores, islands, forests and grasses, buildings, and other natural and cultural landscapes that are attractive to people. Through scientific and reasonable manual intervention to achieve the optimization of comprehensive benefits, areas with characteristic water conservancy and scenic resources background conditions, can better play the potential value in the construction of ecological civilization, and transform towards the goal of "the harmony between man and water".

\section{Overview of the research area}

Qingpu District is located in the southwest of Shanghai, as well as the lower reaches of Lake Tai and the upper reaches of River Huangpu. The territory is flat with dense rivers and a superior ecological environment. The 21 natural lakes of Shanghai, including Lake Dianshan, are located in this district(Fig.1). The water source protection area of the upper reaches of the River Huangpu and the Jinze Reservoir are important sources of drinking water in Shanghai. In addition, there are countryside ecological corridors such as the Qingxi Country Park, the Lake Lanlu Forest, and the River Taipu Forest. They are important ecological spaces and ecology barriers in Shanghai.
Among them, the Lake Dianshan area is rich in water conservancy scenery resources and has a unique location advantage. As early as 2006, it was selected as one of the sixth batches of national Water Parks.

Qingpu is rich in surface water resources, but due to its low-lying terrain, especially the water net polders located in the central and southern low-lying hinterlands of Qingpu, the water level is often above the water level during the flood season. At the same time, the contradiction between the imbalance of water resource allocation and the demand for water resources is prominent, and the contradiction between water qualitytype water shortage and sustainable development is prominent ${ }^{[1]}$. Therefore, how to make use of water resources after rational use of water resources has a certain research value.

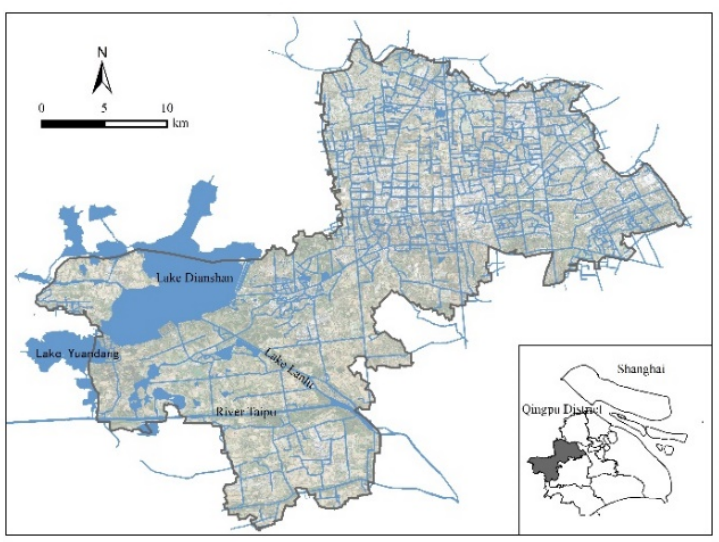

Figure 1. Location map of Qingpu District.

\footnotetext{
*Corresponding author: espi@tongji.edu.cn
} 


\section{Data processing and calculation}

\subsection{Data source}

To ensure the completeness and accuracy of statistical data, we choose years from 2009 to 2019 as the research period. The data mainly comes from Shanghai Statistical Yearbook 2010-2020, Qingpu District Statistical Yearbook, Qingpu District Ecological Environment Status Bulletin, relevant information publicly released from the Water Affairs Bureau, and Ecological Environment Bureau of Qingpu District. The missing data in individual years is supplemented by Lagrange Interpolation Polynomial.

\subsection{Establishment of evaluation index system}

\subsubsection{Reference of related evaluation methods}

When most domestic scholars evaluate water conservancy scenic, they mainly refer to the "Water Conservancy Scenic Area Evaluation Standards"(SL300-2013). Taking a specific water conservancy area as the research object, they have a comprehensive evaluation from the aspects of landscape resources, development and utilization conditions, environmental protection evaluation, and management ${ }^{[2]}$. In the selection of evaluation methods, most scholars use a combination of qualitative and quantitative methods of on-site investigation and questionnaire interviews based on collecting and collating literature data ${ }^{[3]}$. For example, Wang $\mathrm{Li}^{[4]}$ uses the Analytic Hierarchy Process to select evaluation indicators from the five aspects of viewing, ecology, environment, culture, and science according to the characteristics of water conservancy landscape resources in Guangxi, to construct water conservancy landscape resource value evaluation model. Meanwhile, she takes River Chengbi Water Conservancy Scenic Spot as an example for evaluation.
Coupling originally refers to the association and coordination of energy transmission between two or more circuits in physics, and then is gradually used to describe the degree of mutual influence and interaction between two or more systems. In recent years, many scholars have applied coupling analysis to the empirical study of water environment and social development such as urbanization [5-6]. In addition to the state of the water environment, some indicators that reflect the state of the ecological environment are also water conservancy to some extent. The embodiment of natural ecological benefits of landscape resources also has reference value. The social benefits of water conservancy scenery include not only the intuitive changes after the construction of water conservancy projects and the improvement of water transportation and transportation conditions, but also the invisible promotion of the development of agriculture, cultural tourism, and other industries. Especially in Qingpu District, water conservancy is the lifeblood of agriculture, and water culture also constitutes the shape of Qingpu's tourism resources, laying the foundation for the urban development of Qingpu District as "Shangshan City".

\subsubsection{Construction of Comprehensive Benefit Evaluation Index System}

Follow the principles of systematicity, representativeness, and quantification, this paper selects 19 indicators to construct an evaluation index system for the comprehensive benefits of water conservancy and landscape resources from both ecological and social benefits. Ecological benefits are composed of three aspects: comprehensive environmental status, water environment quality, and greening environment. Social benefits are composed of four aspects: cultural tourism, water conservancy project construction, water transportation, and agricultural development.

Table 1. Comprehensive benefits evaluation index system.

\begin{tabular}{|c|c|c|c|c|c|c|}
\hline \multirow{2}{*}{$\begin{array}{l}\text { Serial } \\
\text { number }\end{array}$} & \multirow{2}{*}{$\begin{array}{l}\text { Target } \\
\text { layer }\end{array}$} & \multirow{2}{*}{$\begin{array}{c}\text { System } \\
\text { layer }\end{array}$} & \multicolumn{4}{|c|}{ Index layer } \\
\hline & & & $\begin{array}{l}\text { First level } \\
\text { indicator }\end{array}$ & $\begin{array}{c}\text { Secondary } \\
\text { indicator }\end{array}$ & $\begin{array}{r}\text { Indicator } \\
\text { attributes }\end{array}$ & $\begin{array}{c}\text { Entropy } \\
\text { weight }\end{array}$ \\
\hline 1 & \multirow{3}{*}{$\begin{array}{c}\text { Overall } \\
\text { benefits of } \\
\text { water } \\
\text { conservancy } \\
\text { scenic }\end{array}$} & \multirow{3}{*}{$\begin{array}{c}\text { Ecological } \\
\text { benefits }\end{array}$} & \multirow{3}{*}{$\begin{array}{l}\text { Comprehensive } \\
\text { environmental } \\
\text { status }\end{array}$} & $\begin{array}{l}\text { Biggest water } \\
\text { level change }\end{array}$ & minus & 0.0837 \\
\hline 2 & & & & $\begin{array}{l}\text { Flood season } \\
\text { accounts for } \\
\text { annual } \\
\text { precipitation } \\
\end{array}$ & minus & 0.0784 \\
\hline 3 & & & & $\begin{array}{l}\text { Air quality index } \\
\text { good rate }\end{array}$ & plus & 0.0711 \\
\hline 4 & \multirow{3}{*}{$\begin{array}{c}\text { Overall } \\
\text { benefits of } \\
\text { water } \\
\text { conservancy } \\
\text { scenic }\end{array}$} & \multirow{3}{*}{$\begin{array}{c}\text { Ecological } \\
\text { benefits }\end{array}$} & \multirow{3}{*}{$\begin{array}{c}\text { Water } \\
\text { environmental } \\
\text { quality }\end{array}$} & $\begin{array}{c}\text { Water } \\
\text { environmental } \\
\text { quality }\end{array}$ & minus & 0.0801 \\
\hline 5 & & & & $\begin{array}{c}\text { Comprehensive } \\
\text { pollution index of } \\
\text { main rivers }\end{array}$ & minus & 0.1145 \\
\hline 6 & & & & $\begin{array}{c}\text { Comprehensive } \\
\text { trophic state } \\
\text { index of Dianshan } \\
\text { Lake }\end{array}$ & minus & 0.0752 \\
\hline
\end{tabular}




\begin{tabular}{|c|c|c|c|c|c|c|}
\hline \multirow{2}{*}{$\begin{array}{l}\text { Serial } \\
\text { number }\end{array}$} & \multirow{2}{*}{$\begin{array}{l}\text { Target } \\
\text { layer }\end{array}$} & \multirow{6}{*}{$\begin{array}{l}\text { System } \\
\text { layer }\end{array}$} & \multicolumn{4}{|c|}{ Index layer } \\
\hline & & & $\begin{array}{l}\text { First level } \\
\text { indicator }\end{array}$ & $\begin{array}{c}\text { Secondary } \\
\text { indicator }\end{array}$ & $\begin{array}{l}\text { Indicator } \\
\text { attributes }\end{array}$ & $\begin{array}{c}\text { Entropy } \\
\text { weight }\end{array}$ \\
\hline 7 & & & & $\begin{array}{l}\text { Average industrial } \\
\text { wastewater } \\
\text { discharge }\end{array}$ & minus & 0.1171 \\
\hline 8 & & & & $\begin{array}{l}\text { Urban sewage } \\
\text { treatment rate }\end{array}$ & plus & 0.1991 \\
\hline 9 & & & & Green area rate & plus & 0.0919 \\
\hline 10 & & & $\begin{array}{c}\text { Green } \\
\text { environment }\end{array}$ & $\begin{array}{c}\text { Water } \\
\text { conservation } \\
\text { forest area }\end{array}$ & plus & 0.0889 \\
\hline 11 & & & & $\begin{array}{c}\text { Receive tourist } \\
\text { visits throughout } \\
\text { the year }\end{array}$ & plus & 0.0800 \\
\hline 12 & & & Cultural tourism & $\begin{array}{c}\text { Number of } \\
\text { visitors to cultural } \\
\text { science } \\
\text { exhibitions }\end{array}$ & plus & 0.2674 \\
\hline 13 & & & & $\begin{array}{c}\text { The population of } \\
\text { water } \\
\text { conservancy } \\
\text { dykes }\end{array}$ & plus & 0.1191 \\
\hline 14 & & & Water & $\begin{array}{l}\text { Green coverage } \\
\text { rate of } \\
\text { embankment }\end{array}$ & plus & 0.0706 \\
\hline 15 & & $\begin{array}{c}\text { Social } \\
\text { benefits }\end{array}$ & $\begin{array}{l}\text { conservancy } \\
\text { project } \\
\text { construction }\end{array}$ & $\begin{array}{l}\text { The proportion of } \\
\text { the area with } \\
\text { guaranteed } \\
\text { harvest during } \\
\text { droughts and } \\
\text { floods in the } \\
\text { effective } \\
\text { irrigation area }\end{array}$ & plus & 0.0786 \\
\hline 16 & & & Water & $\begin{array}{l}\text { Water transport } \\
\text { volume }\end{array}$ & plus & 0.0816 \\
\hline 17 & & & transportation & $\begin{array}{c}\text { Water transport } \\
\text { turnover }\end{array}$ & plus & 0.0792 \\
\hline 18 & & & & $\begin{array}{l}\text { Per capita gross } \\
\text { agricultural } \\
\text { product } \\
\end{array}$ & plus & 0.1210 \\
\hline 19 & & & $\begin{array}{l}\text { Agricultural } \\
\text { development }\end{array}$ & $\begin{array}{c}\text { Production of } \\
\text { aquatic products } \\
\text { per aquaculture } \\
\text { area } \\
\end{array}$ & plus & 0.1025 \\
\hline
\end{tabular}

\subsection{Entropy method data processing}

\subsubsection{Standardized processing}

Since the unit, magnitude, and attribute of the original value of each indicator in the evaluation system are different, in order to eliminate the influence of the above factors on the evaluation result, the original value of each indicator is first standardized according to the normalization method. In other words, the absolute value of the original data of each indicator is converted into a relative value through standardization, so that different indicators are more comparable. Positive indicators indicate that larger indicators are more conducive to the coupling between ecological benefits and social benefits of water conservancy scenic, while reverse indicators indicate that larger indicators are less conducive to the coupling between comprehensive benefits. Namely:

Positive index ("+") :

$$
\mathbf{Y}_{i j}=\frac{\mathbf{X}_{i j}-\min \mathbf{X}_{i j}}{\max \mathbf{X}_{i j}-\min \mathbf{X}_{i j}}
$$

Negative index (“_”) :

$$
\mathbf{Y}_{i j}=\frac{\max \mathbf{X}_{i j}-\mathbf{X}_{i j}}{\max \mathbf{X}_{i j}-\min \mathbf{X}_{i j}}
$$


$\mathbf{Y}_{i j}$ is the standardized value of the index item in the year; $\mathbf{X}_{i j}$ is the original value of the index item in the year, $\max \mathbf{X}_{i j}$ and $\min \mathbf{X}_{i j}$ are the maximum and minimum values in the original value of the index item in the year ( $i$ is the year; $j$ is the quantity of each system index.)

\subsubsection{Setting of indicator weight}

Since the natural logarithm is needed to calculate the information entropy, the index value cannot be 0 , so the translation processing of 0.01 is required, that is, let $\mathbf{H}=$ $\mathbf{Y}+\mathrm{d}$, where $\mathrm{d}$ is a positive number that makes it slightly greater than 0 , and 0.01 is here.

$$
\mathbf{P}_{i j}=\frac{\mathbf{H}_{i j}}{\sum_{i=1}^{n} \mathbf{H}_{i j}} \quad\left(0 \leq \mathbf{P}_{i j} \leq 1\right)
$$

\subsubsection{Entropy calculation}

Calculate the entropy value of the jth index.

$$
\mathbf{E}_{j}=-\frac{1}{\ln n} \sum_{i=1}^{n_{N} m} \mathbf{P}_{i j} \ln \left(\mathbf{P}_{i j}\right)\left(0 \leq \mathbf{E}_{j} \leq 1\right)
$$

\subsubsection{Calculation of difference coefficient}

Directly subtract the entropy value of this indicator from 1 to get the coefficient of difference.

$$
\mathbf{G}_{j}=1-\mathbf{E}_{j}
$$

3.3.5 Calculate the weight of the $j$ th indicator in each system

$$
\mathbf{W}_{j}=\frac{\mathbf{G} \boldsymbol{j}}{\sum_{i=1}^{m} \mathbf{G} j}
$$

\subsubsection{Comprehensive evaluation index calculation}

Multiply the obtained index weight and the ratio of the data of the jth year on the evaluation index to obtain the comprehensive score of each evaluation index(Tab.1).

$$
\mathbf{U}_{i j}=\sum_{i=1}^{n} \mathbf{W}_{j} \mathbf{P}_{i j}
$$

\subsection{Calculation of coupling degree and coupling coordination degree}

In order to measure and evaluate the degree of coordinated development of ecological and social systems in the comprehensive benefits of water conservancy scenic, the coupling degree and coupling coordination degree are introduced. The calculation formula is:

$$
\mathbf{C}=\left[\frac{\mathbf{U}_{1} \times \mathbf{U}_{2}}{\left(\frac{\mathbf{U}_{1}+\mathbf{U}_{2}}{2}\right)^{2}}\right]^{1 / 2}
$$

$\mathbf{C}$ is the coupling degree, $\mathbf{C}_{1}$ and $\mathbf{C}_{2}$ are the comprehensive coordination indexes of ecological and social subsystems respectively. $\mathbf{C} \in[0,1]$, the larger the value of $\mathbf{C}$, the stronger the coupling effect between systems is. Although the degree of coupling can quantitatively analyze the degree of mutual influence between the various subsystems, it cannot reflect the comprehensive development level of the research system, and it is difficult to measure the overall effectiveness of the research system ${ }^{[7]}$. Therefore, a coupling coordination degree model must be constructed. The calculation formula is:

$$
\mathbf{D}=\sqrt{\mathbf{C} \times \mathbf{T}}, \quad \mathbf{T}=\alpha \mathbf{U}_{1}+\beta \mathbf{U}_{2}
$$

D is the coupling coordination degree and the value range is $[0,1]$. $\alpha$ and $\beta$ are undetermined parameters, and the sum is 1 . Since the ecological and social aspects of the comprehensive benefits of water conservancy and landscape have the same status, both $\alpha$ and $\beta$ are taken as $1 / 2$ in this study.

\section{Result analysis}

\subsection{Evolution characteristics of the comprehensive development index of water conservancy scenic}

\subsubsection{Ecological benefits}

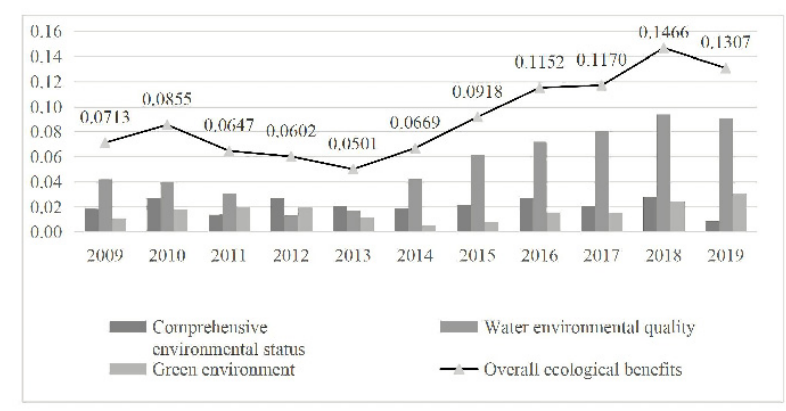

Figure 2. Changes in the comprehensive index of various indicators of ecological benefits. 
It can be seen from Fig.2 that since 2014, the comprehensive index of water environment quality in Qingpu District has increased year by year, driving the increase in the overall index of the ecological benefit system. The comprehensive index of the greening environment has experienced two stages - decrease in the early stage and then increase, and it shows an increasing change year by year after 2014. There is no obvious change rule in the comprehensive environmental quality comprehensive index, indicating that the state of the natural environment is greatly affected by nature.

In order to fully realize the water environment governance goal of "clear water, green shores, smoothness, beautiful scenery, and ecology", in recent years, Qingpu District has taken advantage of the construction of the national water ecological civilization city to vigorously rectify and protect the water environment and promote the River and Lake System in an all-round way. Meanwhile, it pays more attention to water conservation, safety protection, and greening construction. On the whole, the environmental quality is showing an improvement trend, and the effect of water control and district development is gradually showing, but the overall level is still not high.

\subsubsection{Social benefits}

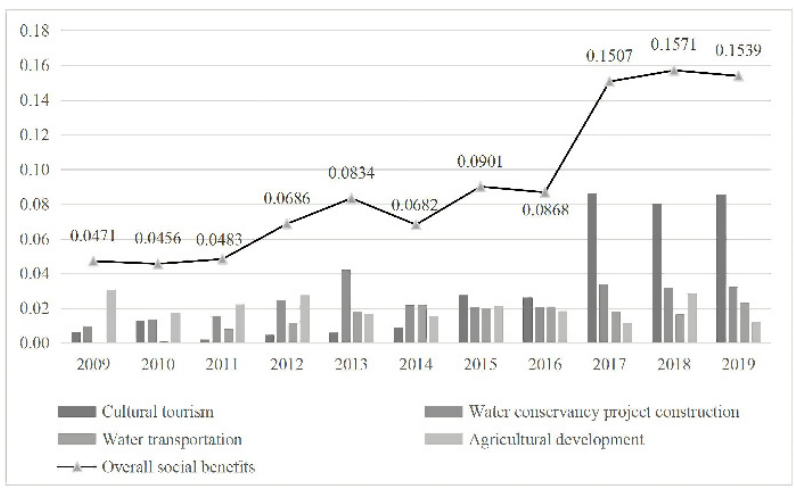

Figure 3. Changes in the comprehensive index of various indicators of social benefits.

It can be seen from Fig. 3 that the social benefits of the water conservancy scenery in Qingpu District are showing an upward trend. From 2009 to 2019, cultural tourism, water conservancy project construction, and water transportation have developed rapidly. Especially from 2016 to 2017, the annual increase in the number of tourists and the number of visitors to cultural science exhibitions nearly doubled, driving social benefits to achieve explosive growth. In contrast, water conservancy scenery has a weak supporting role in agricultural development, and the per capita gross agricultural production value and the output of aquatic products per unit of aquaculture area fluctuate repeatedly in a small range. Of course, this is also related to the impact of agricultural production statistics on the fluctuations in the prices of agricultural products that year.

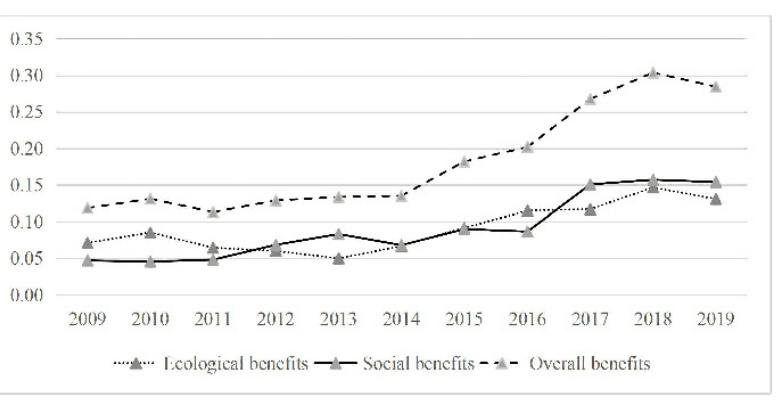

Figure 4. Change trend of the comprehensive index of comprehensive benefits system.

(Fig.4)For Qingpu, a hub town that connects Shanghai with Jiangsu and Zhejiang, water transportation has great utility value, which is reflected in the rapid growth of water transportation volume and water transportation turnover. In addition, in recent years, the Qingpu District Water Affairs Bureau has focused on promoting the reform and development of water conservancy, the water conservancy disaster prevention and reduction system has been continuously improved, the construction of rural water conservancy infrastructure has continued to be consolidated, and the construction of water ecological civilization has accelerated, providing a strong force for the sustainable economic and social development of water conservancy support and protection of the entire district.

\subsection{Coupling analysis of comprehensive benefits of water conservancy scenic}

Regarding the classification of ecological civilization coordination types in the relevant research literature ${ }^{[8]}$, according to the degree of coupling coordination, the degree of coupling coordination of the various subsystems of comprehensive benefits of water conservancy and landscape resources is divided into 4 stages, namely $0<$ $\mathbf{D} \leq 0.3,0.3<\mathbf{D} \leq 0.5,0.5<\mathbf{D} \leq 0.7,0.8<\mathbf{D} \leq 1$, respectively corresponding to the low-level coupling coordination stage, the antagonist stage, the primary coordination stage, and the high-level coupling stage.

From the calculation results, it can be seen that the coupling degree is above 0.9 , indicating that the social and ecological benefits of the water conservancy scenery in Qingpu District are close to each other, which is a very strong coupling. The level of coupling coordination is between 0.23 and 0.39 , and the overall shift is in the direction of optimization. During the period from 2009 to 2014, the coordination index fluctuated slightly but the amplitude was small. Starting from 2015, the coordination state has moved from a moderately unbalanced stage to a mildly unbalanced stage, and the degree of coupling coordination has shown a slow upward trend. It can be seen that the construction of ecological civilization related to water conservancy and scenery in Qingpu District has achieved certain results in the past ten years, but it is still in the low-level coupling and coordination stage, and there is still a lot of room for development in the future. 
Table 2. Evaluation results and coupling coordination degree of comprehensive benefits of water conservancy scenic in Qingpu District.

\begin{tabular}{|c|c|c|c|c|c|c|}
\hline Years & $\begin{array}{c}\text { Ecological } \\
\text { benefits index }\end{array}$ & $\begin{array}{c}\text { Social } \\
\text { benefits Index }\end{array}$ & $\begin{array}{l}\text { Comprehensive } \\
\text { benefits Index }\end{array}$ & $\begin{array}{c}\text { Coupling } \\
\text { degree }\end{array}$ & $\begin{array}{c}\text { Coupling } \\
\text { coordination } \\
\text { degree } \\
\end{array}$ & $\begin{array}{c}\text { Coordination } \\
\text { status }\end{array}$ \\
\hline 2009 & 0.0713 & 0.0471 & 0.1184 & 0.9790 & 0.2408 & \multirow{6}{*}{$\begin{array}{l}\text { Moderate } \\
\text { disorder }\end{array}$} \\
\hline 2010 & 0.0855 & 0.0456 & 0.1311 & 0.9525 & 0.2499 & \\
\hline 2011 & 0.0647 & 0.0483 & 0.1130 & 0.9895 & 0.2365 & \\
\hline 2012 & 0.0602 & 0.0686 & 0.1289 & 0.9979 & 0.2536 & \\
\hline 2013 & 0.0501 & 0.0834 & 0.1335 & 0.9684 & 0.2542 & \\
\hline 2014 & 0.0669 & 0.0682 & 0.1351 & 1.0000 & 0.2599 & \\
\hline 2015 & 0.0918 & 0.0901 & 0.1820 & 1.0000 & 0.3016 & \multirow{5}{*}{$\begin{array}{l}\text { Mild } \\
\text { disorder }\end{array}$} \\
\hline 2016 & 0.1152 & 0.0868 & 0.2020 & 0.9901 & 0.3162 & \\
\hline 2017 & 0.1170 & 0.1507 & 0.2677 & 0.9920 & 0.3644 & \\
\hline 2018 & 0.1466 & 0.1571 & 0.3037 & 0.9994 & 0.3896 & \\
\hline 2019 & 0.1307 & 0.1539 & 0.2847 & 0.9967 & 0.3767 & \\
\hline
\end{tabular}

\section{Conclusion and Outlook}

\subsection{Research conclusion}

Under the development goal of building an ecological region of rivers and lakes with characteristics of history, culture, and environment in southern China, the research on the water conservancy scenic of Qingpu District, especially the measurement and evaluation of comprehensive benefits, has high practical significance and application value. However, the current related research lacks investigation about quantitative coupling and coordination. Therefore, this study selects 19 index factors from two aspects of ecological benefit and social benefit, uses the entropy method to comprehensively evaluate the water conservancy scenic benefits of Qingpu District from 2009 to 2019, and uses the coupling coordination degree model to evaluate the comprehensive benefits subsystem. The following conclusions were drawn from the comprehensive measurement and analysis: from 2009 to 2019, the overall benefits of water conservancy scenic in Qingpu District showed an upward trend, especially after 2014. The social benefit slowly rises amidst fluctuations, and the ecological benefit goes through two phases of change, which first drops and then rises. During the period from 2009 to 2014, the coordination index fluctuated slightly. Starting from 2015, the coordination state has changed from the stage of moderate imbalance to the stage of mild imbalance.

Objective analysis, this study uses the entropy method to determine the weight of each evaluation index, which can reduce the error caused by human subjective factors. Since there is not much quantitative statistical data at present, it is relatively difficult to obtain other index data. In addition, the connotation of comprehensive benefits of water conservancy scenic is relatively rich, and the index system and research perspectives still need to be further improved. In the later stage, further in-depth research can be conducted from the perspective of the spatial differences of internal areas within Qingpu District.

\subsection{Outlook}

With the implementation of the River and Lake System in various places in recent years, the concept of harmonious coexistence between man and nature has gradually sunk deep into people's minds. As the model for the construction of beautiful rivers and lakes, water conservancy scenic has gradually increased its role in regional tourism. Qingpu District is included in the Yangtze River Delta Integration Demonstration Zone in 2019 because it happens to be at the junction of the three provinces and cities of Shanghai, Jiangsu, and Zhejiang. Among them, Zhujiajiao Town and Jinze Town are the first start-up areas. In recent years, under the goal of promoting the ecological quality construction of the demonstration area, Qingpu District has not only created new highlands of ecological value such as Lake Dianshan and Lake Yuandang, but the urban water system landscape of the water system park around the city has also gradually taken shape. Qingpu Water Gate and Shangshan Square have become "Instagram Worthy Locations". Meanwhile, the "blue pearl chain" leisure landscape belt planning has been taken into the agenda. With expectations of further improving the comprehensive benefits of water conservancy and scenery in Qingpu District, and strengthen the penetration and integration between ecological and social systems, this article puts forward the following suggestions.

First, it is important to make full use of Qingpu's existing ecological, cultural, and location advantages to strengthen the building of cultural tourism brands. At present, the characteristics of scenic spots in the area around Lake Dianshan are not outstanding enough, especially the brand influence advantage of the three ancient towns in Qingxi has not yet been established. The water culture core of "Shangshan City" should be deeply explored to form a tourism brand with international influence. Second, strengthen the comprehensive utilization of the waterfront area. The current ratio of construction land to ecological space in Qingpu District is 
3:7, which means the man-land relationship is suitable. The rural landscape resources of the water village are rich, and there is a large amount of waterfront space to be developed. Only by implanting characteristic waterfront functions in the construction of ecological landscape and highlighting the characteristics of water conservancy, can it become an important window for displaying water conservancy and publicizing water conservancy to the public.

\section{References}

1. Y. Zhao, F. Ye. Rural Economy and Science. 28(14): $1+3(2017)$

2. L. L. An. Haihe Water Resources. 227(1):31-33(2021)

3. C. Feng, Q. Xue, F. Xu, et al. China Water Resources. 798(12): 50, 57-60(2016)

4. L. Wang, H. J. Ren, H. Huang, et al. Technology Innovation and Application. (01): 142-145(2016)

5. A. L. Chen, T. Lin, Y. P. Zhong, et al. Energy and Environment. (01):8-11 (2021)

6. R. H. Yuan, Y. Q. Zang. Journal of Economics of Water Resources. 39(02):1-8+95. (2021)

7. M. Q. Wang, J. D. Wang, J. S. Liu, et al. Chinese Journal of Applied Ecology. 20(01):170-176. (2009)

8. H. F. Jia, X. Qing. Jiangsu Agriculture Sciences. 49(02):217-222. (2021) 